\title{
Clinical Application of Newborn Umbilical Vein Catheterization Combining with PICC
}

\author{
Patiman Tuerhong \\ Neonatology of Maternity and Child Care Hospital, Urumqi, China \\ Email: mlbsabc@sina.com
}

How to cite this paper: Tuerhong, P. (2017) Clinical Application of Newborn Umbilical Vein Catheterization Combining with PICC. Journal of Biosciences and Medicines, 5, 1-7.

https://doi.org/10.4236/jbm.2017.55001

Received: April 18, 2017

Accepted: May 21, 2017

Published: May 24, 2017

Copyright $\odot 2017$ by author and Scientific Research Publishing Inc. This work is licensed under the Creative Commons Attribution International License (CC BY 4.0).

http://creativecommons.org/licenses/by/4.0/ (c) (i) Open Access

\begin{abstract}
Purpose: Research on clinical application effect of combining very low birth weight newborn (VLBWN) umbilical vein catheterization (UVC) with peripherally inserted central catheter (PICC). Method: 60 cases of VLBWN checked in our hospital's ICU are selected and divided into combination group $(\mathrm{n}=30)$ and PICC group $(\mathrm{n}=30)$ according to the random number table. Combination of UVC and PICC is applied on newborn of combination group while only PICC is applied on newborn of PICC group. These two groups' newborn's PICC catheterization operation time, PICC indwelling time, weight gain, hospital stays, hospital infection, planned extubation, successful single puncture, adverse events and other indexes are observed. Result: Newborns in combination group have less PICC catheterization operation time and less hospital stays than newborns in PICC group while newborns in combination group have longer PICC indwelling time and greater weight gain than newborns in PICC group. The difference here has statistical significance $(\mathrm{p}<0.05)$. Combination group's hospital infection ratio $(3.33 \%)$ is lower than that of PICC group (23.33\%). The difference here has statistical significance ( $\mathrm{p}$ $<0.05)$. Newborns in combination group have a planned extubation rate of 93.33\% and a successful single puncture rate of $93.33 \%$, which are greater than those of newborn in PICC group (respectively $73.33 \%$ and $70.00 \%$ ). The difference here has statistical significance $(\mathrm{p}<0.05)$. Newborns in combination group have an adverse event occurrence rate of $43.33 \%$, lower than that of PICC group (70.00\%). The difference here has statistical significance $(\mathrm{p}<$ 0.05). Conclusion: Application of combination of UVC and PICC on VLBWN can greatly improve PICC catheterization efficiency and newborn patients' nutriture and reduce rate of complications, thus, it is worthy of clinical application.
\end{abstract}

\section{Keywords}

Very Low Birth Weight Newborn (VLBWN), Umbilical Vein 
Catheterization (UVC), Peripherally Inserted Central Catheter(PICC), Nutrition, Complication

\section{Introduction}

Very low birth weight newborn (VLBWN) with mal developed digestive system and multiple complications often have feeding intolerance and need intravenous nutrition to ensure their normal growth. Data displaying VLBWN are often accompanied with symptoms of edema, low body temperature, disorder of vital signs, peripheral vascular insufficiency and so on, and clinic often uses peripherally inserted central catheter (PICC) to give them medicine and nutrition, which is safe and convenient with simple operation and long catheter time. Clinical practice proves although application of PICC on VLBWN achieves a good result, pure application of PICC has problems of low success rate of puncture, tube plugging and so on, influencing nutrition supply and rescue and dosing. Umbilical vein catheterization (UVC) is an extremely important life path for VLBWN and it can be used in infusion of medicine, venous parenteral nutrition, monitoring central venous pressure and blood exchange. However, UVC is likely to lead to infection of VLBWN. The longer the indwelling time of UVC is, the higher the infection rate of VLBWN is. What's more, UVC is strict with VLBWN's age in days [1]. Ye Chunyan et al. [2] apply combination of UVC and PICC on VLBWN, and the results show that the combination of the two can shorten the PICC operation time, improve the success rate of one-off PICC puncture and reduce the complication rate. Yu Xinying et al. [3] make studies to prove that combination of UVC and PICC on VLBWN can effectively reduce the complication rate. It provides reference for the clinic to study the application effect of combination of UVC and PICC on VLBWN. Our hospital applies combination of UVC and PICC on VLBWN from January 2015 to December 2016, achieving satisfactory effects. Report is as follows.

\section{Materials and Methods}

\subsection{General Data}

Select 60 cases of VLBWN checked in our hospital's ICU from January 2015 to December 2016 with 38 males (63.33\%) and 22 females (36.67\%). Their age is 5 to $10 \mathrm{~d}$ with an average of $(7.12 \pm 0.62) \mathrm{d}$; their gestational age is 28 to 34 weeks with an average of $(30.41 \pm 3.49)$ weeks; their birth weight is 0.83 to $1.50 \mathrm{~kg}$, with an average of $(1.24 \pm 0.21) \mathrm{kg}$. Complication: 47 hyaline membrane disease newborn patients $(78.33 \%), 8$ mild asphyxia patients $(13.33 \%)$ and 5 respiratory distress syndrome patients $(8.33 \%)$. Inclusion criteria: newborn patients conforming to judgment standard of VLBWN (the birth weight is $1 \sim 1.5 \mathrm{~kg}$ ); birth weight $<1.50 \mathrm{~kg}$ newborn patients; stable life signs newborn patients; newborn patients with normal blood clotting time, blood platelet count and D-2 polymers; parents or guardian informed consent newborn patients. Exclusion crite- 
ria: umbilical region deformity newborn patients; dry umbilical cord newborn patients; low ligation umbilical cord newborn patients; newborn patients with severe disease of the heart and kidney; newborn patients with autoimmune disease; newborn patients with omphalitis, bacteremia and systemic severe infection; poor compliance newborn patients. Divide these 60 cases of VLBWN into combination group $(n=30)$ and PICC group $(n=30)$ based on random number table and these two groups of VLBWN's baseline information discrepancy has no statistical significance $(\mathrm{p}>0.05)$. Please refer to Table 1 .

\subsection{Method}

1) Combination group

Combination of UVC and PICC is applied on newborn in combination group. When admitted to hospital, newborn are given UVC. Fetch 3.5 Fr umbilical venous catheter (manufacturing enterprise: American UATH Company), insert it to the desired depth under strict aseptic condition, firmly fix it after confirming smooth blood flowing through blood transfusion, conduct $\mathrm{x}$-ray location at the bedside, place distal end of umbilical vein catheter inside the 8th to the 10th thoracic vein properly and apply purse string suture on umbilical cord stump. If the location is improper, umbilical venous catheter can be retreated to the most unobstructed blood return part to conduct re-fixation in order to make distal end of umbilical vein catheter between the 3rd and the 4th lumbar vertebra (low order method). Under normal conditions, indwelling time of umbilical venous catheter is about 7 days with a maximum of not more than 10 days. On the day of removing the umbilical venous catheter, take a $1.9 \mathrm{Fr}$ catheter, insert the PICC catheter in newborn patients' elbow vein under strict aseptic conditions, conduct $\mathrm{x}$-ray location at the bedside, confirm PICC catheter's distal end is in the proper place, conduct venous transfusion on newborn patients after proper fixation and make sure PICC catheter is smooth during transfusion.

2) PICC group

Newborn patients in PICC group only receive PICC. On the admission day, the 1.9 Fr catheter is inserted in the newborn's elbow vein and the specific operation is the same as the combination group inserting the PICC catheter.

3) Observational index

Table 1. Comparison between the two groups of VLBWN's baseline information.

\begin{tabular}{|c|c|c|c|c|c|c|}
\hline Group & $\mathrm{N}$ & $\begin{array}{c}\text { Gender } \\
\text { (male/female) }\end{array}$ & $\begin{array}{c}\text { Gestational age } \\
\text { (week) }\end{array}$ & Age in days & $\begin{array}{l}\text { Birth weight } \\
\quad(\mathrm{kg})\end{array}$ & $\begin{array}{c}\text { Complication (hyaline } \\
\text { membrane disease/mild } \\
\text { asphyxia/respiratory distress } \\
\text { syndrome) }\end{array}$ \\
\hline $\begin{array}{l}\text { Combination } \\
\text { group }\end{array}$ & 30 & $20 / 10$ & $30.21 \pm 3.38$ & $6.06 \pm 0.59$ & $1.22 \pm 0.17$ & $23 / 5 / 2$ \\
\hline PICC group & 30 & $18 / 12$ & $30.45 \pm 3.55$ & $6.15 \pm 0.66$ & $1.26 \pm 0.24$ & $24 / 3 / 3$ \\
\hline $\mathrm{x} 2 / \mathrm{t}$ & & 0.2871 & 0.2682 & 0.5568 & 0.7449 & 0.7213 \\
\hline $\mathrm{p}$ & & 0.5921 & 0.7895 & 0.5798 & 0.4593 & 0.6972 \\
\hline
\end{tabular}


Observe the two group's newborn patients' PICC catheterization operation time, PICC indwelling time, weight growth and hospital stays; hospital infection, planned extubation, successful one-time puncture; bronchopulmonary dysplasia (BPD), retinopathy of prematurity (ROP), intracranial hemorrhage (IVH), necrotizing enterocolitis (NEC), patent ductus arteriosus (PDA) and other adverse events occurrence indexes. PICC catheterization operation time starts from tying tourniquet to finish time of X-ray location of position of cacumen of PICC and fixation of catheter. One-time successful puncture refers to the puncture needle enters blood vessel in a one-time puncture and PICC catheter can enter blood vessel successfully after retreat of core needle.

\subsection{Statistical Treatment}

Use SPSS 19.0 statistic software to analyze, measurement data is expressed by $\mathrm{x} \pm$ $\mathrm{s}$, conduct comparison paired t test within the group, and conduct comparison independent sample $t$ test within the group; enumeration data is shown in case number and percentage, conduct $\mathrm{x}^{2}$ test, and $\mathrm{p}<0.05$ means that difference between groups has statistical significance.

\section{Results}

\subsection{Comparison between Two Groups of Newborn Patients' PICC Catheterization Operation Time, PICC Indwelling Time, Weight Growth and Hospital Stay}

PICC catheterization operation time and hospital stay of combination group are less than those of PICC group, and the difference here has statistical significance $(\mathrm{p}<0.05)$. PICC indwelling time and weight growth of combination group are greater than those of PICC group, and the difference here has statistical significance $(\mathrm{p}<0.05)$. Please refer to Table 2.

\subsection{Comparison between Two Groups of Newborn Patients' Hospital Infection, Planned Extubation and Successful One-Time Puncture}

Infection rate $(3.33 \%)$ of combination group is lower than that $(23.33 \%)$ of PICC group and the difference here has statistical significance $(\mathrm{p}<0.05)$; combination

Table 2. Comparison between two groups of newborn patients' PICC catheterization

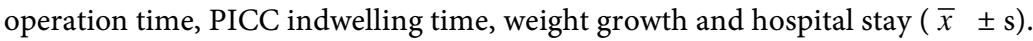

\begin{tabular}{|c|c|c|c|c|c|}
\hline Group & $\mathrm{N}$ & $\begin{array}{l}\text { PICC } \\
\text { catheterization op- } \\
\text { eration time (min) }\end{array}$ & $\begin{array}{c}\text { PICC } \\
\text { indwelling time }(\mathrm{d})\end{array}$ & $\begin{array}{l}\text { Weight growth } \\
\qquad(\mathrm{g} / \mathrm{kg} \cdot \mathrm{d})\end{array}$ & Hospital stay (d) \\
\hline $\begin{array}{l}\text { Combinatio } \\
\text { n group }\end{array}$ & 30 & $26.68 \pm 2.73$ & $24.39 \pm 2.50$ & $11.84 \pm 1.13$ & $39.93 \pm 4.12$ \\
\hline PICC group & 30 & $35.94 \pm 3.64$ & $20.58 \pm 2.21$ & $10.35 \pm 1.02$ & $47.93 \pm 4.84$ \\
\hline $\mathrm{t}$ & & 11.1471 & 6.2540 & 5.3611 & 6.8938 \\
\hline $\mathrm{p}$ & & 0.0000 & 0.0000 & 0.0000 & 0.0000 \\
\hline
\end{tabular}


group's planned extubation rate (93.33\%) and successful one-time puncture rate (93.33\%) are higher than those of PICC group(respectively are $73.33 \%$ and $70.00 \%)$, and the difference here has statistical significance $(\mathrm{p}<0.05)$. Please refer to Table 3.

\subsection{Comparison between Two Groups of Newborn Patients' Adverse Events Occurrence}

Combination group's adverse events occurrence rate $(43.33 \%)$ is lower than that (70.00\%) of PICC group, and the difference here has statistical significance $(\mathrm{p}<$ 0.05). Please refer to Table 4.

\section{Discussion}

VLBWN's multiple disease is serious and most newborn patients have mal developed gastrointestinal function leading to failure in obtaining adequate nutrition through digestive system within a short time after birth, therefore it is necessary to adopt infusion of medicine and nutrition in a long time. Since newborn patients' state of illnesses change rapidly, the venous channel must stay smooth at any time to maintain normal growth and to control disease. Application of UVC combining with PICC on VLBWN can provide parenteral nutrition and therapeutic for patients to ensure their normal growth. However, since VLBWN's blood vessel is thin and small and most blood vessels are malformed, it is difficult to achieve successful one-time puncture after applying PICC immediately after birth. Repeated puncture is likely to lead to newborn patients' apnea, intracranial hemorrhage and other adverse reactions [4]. Research proves

Table 3. Comparison between two groups of newborn patients' hospital infection, planned extubation and successful one-time puncture $[\mathrm{n}(\%)]$.

\begin{tabular}{ccccc}
\hline Group & $\mathrm{N}$ & $\begin{array}{c}\text { Hospital } \\
\text { infection }\end{array}$ & $\begin{array}{c}\text { Planned } \\
\text { extubation }\end{array}$ & $\begin{array}{c}\text { Successful one-time } \\
\text { puncture }\end{array}$ \\
\hline $\begin{array}{c}\text { Combination } \\
\text { group }\end{array}$ & 30 & $1(3.33)$ & $28(93.33)$ & $28(93.33)$ \\
PICC group & 30 & $7(23.33)$ & $22(73.33)$ & $21(70.00)$ \\
$\mathrm{t}$ & 5.1923 & 4.3200 & 5.4545 \\
$\mathrm{p}$ & 0.0227 & 0.0377 & 0.0195 \\
\hline
\end{tabular}

Table 4. Comparison between two groups of newborn patients' adverse events occurrence $[\mathrm{n}(\%)]$.

\begin{tabular}{cccccccc}
\hline Group & $\mathrm{N}$ & BPD & $\begin{array}{c}\text { ROP } \\
(\geq \text { level 2) }\end{array}$ & $\begin{array}{c}\text { IVH }(\geq \text { level } \\
3)\end{array}$ & $\begin{array}{c}\text { NEC } \\
(\geq \text { phase } \quad \text { II })\end{array}$ & PDA & In total \\
\hline $\begin{array}{c}\text { Combinat } \\
\text { ion group }\end{array}$ & 30 & $2(6.67)$ & $4(13.33)$ & $2(6.67)$ & $2(6.67)$ & $3(10.00)$ & $13(43.33)$ \\
$\begin{array}{c}\text { PICC } \\
\text { group }\end{array}$ & 30 & $5(16.67)$ & $6(20.00)$ & $4(13.33)$ & $5(16.67)$ & $5(16.67)$ & $21(70.00)$ \\
$\mathrm{t}$ & & 1.4555 & 0.4800 & 0.7407 & 1.4555 & 0.5769 & 4.3439 \\
$\mathrm{p}$ & 0.2276 & 0.4884 & 0.3894 & 0.2276 & 0.4475 & 0.0371 \\
\hline
\end{tabular}


most VLBWN's umbilical veins are clearly visible and easy to insert the catheter, using less time than PICC puncture and avoiding repeated puncture. But UVC is deep vein catheterization and long retention is likely to cause infection, therefore retention time is within 10 days generally. This period of time is crucial for newborn patients' catch-up growth. If failing to provide nutrition and medicine for newborn patients through periphery catheterization, patients' normal growth will be hindered and many complications will appear with several cases of leading to patients' death [5]. Data display that, after UVC catheterization, newborn patients' vascular development is quite mature and their state of illnesses gets stable gradually, therefore applying PICC on patients can effectively improve successful one-time puncture rate during this period of time [6].

Research by Zhong Wenhua and other people [7] proves that, application of UVC combining with PICC on VLBWN can effectively promote patients' growth, and reduce catheter-related infection rate and hospital stay. In her research, Zhao Xiaoyan [8] discovers that, sequential application of UVC and PICC can improve growth rate of VLBWN's weight and reduce occurrence rate of complications and hospital infection and reduce hospital stay. In the research, combination group's all observational indexes are better than PICC group's, implying that application of UVC combining with PICC on VLBWN have more advantages than pure application of PICC. The combination of UVC and PICC on VLBWN has significant effect but UVB is not suitable for some newborns, such as the VLBWNs with omphalitis, peritonitis, umbilical bulging, necrotizing enterocolitis, localized blood supply disorders on hip or lower limbs have contraindication for UVC. Additionally, the umbilical cord will be dry in $2 \sim 3 \mathrm{~d}$ after VLBWN's birth, it is difficult to operate UVC, usually the best catheterization time is at $15 \sim 30$ min after birth; the UVC will not be operated for most of the VLBWNs more than $4 \mathrm{~d}$ after birth.

\section{Conclusion}

In conclusion, application of UVC combining with PICC on VLBWN can reduce catheterization operation time and hospital stay, increase PICC indwelling time, enhance newborn patients' weight growth rate, planned extubation rate and successful one-time puncture rate and reduce hospital infection rate and occurrence rate of complications. Besides, it is safer. Therefore, it is worthy of being applied to clinical practice.

\section{References}

[1] Li, N., Qu, Q.R., Guo, H.X., et al. (2016) Application Effect of Umbilical Vein Catheterization Combining with PICC on VLBWN. Disease Surveillance and Control Magazine, 10, 1005-1006.

[2] Ye, C.Y., Li, H.L., Zhu, C.J., et al. (2015) Effect Observation of the Combination of UVC and PICC for the VLBWNs. Nursing Journal, 22, 59-62.

[3] Li, N., Qu, Q.R., Guo, H.X., et al. (2016) Application Effect of the Combination of UVC and PICC for the VLBWNs. Journal of Disease Surveillance and Control, 10, 1005-1006. 
[4] Yang, Z.M., Wang, S.N. and Ma, Y.L. (2013) Application of Umbilical Vein Combining with PICC on VLBWN. Chinese Journal of Contemporary Pediatrics, 15, 353-355.

[5] Zhu, H. (2013) Newborn UVC and PICC Combined Application Clinical Research. Fujian Medical Journal, 35, 29-31.

[6] Xu, X.J. (2015) Clinical Application of Umbilical Vein Catheterization in Salvage of VLBWN. Guangzhou Medical University Journal, 43, 129-131.

[7] Zhong, W.H., Yang, R.W., Huang, H.F., et al. (2016) Application of Umbilical Vein Catheterization Combining with PICC on VLBWN. Zhejiang Practical Medicine, 21, 50-52.

[8] Zhao, X.Y. (2016) Clinical Efficacy Observation on Sequential Application of Umbilical Vein and PICC on VLBWN. Public Medical Forum Magazine, 20, 3874-3875.

Submit or recommend next manuscript to SCIRP and we will provide best service for you:

Accepting pre-submission inquiries through Email, Facebook, LinkedIn, Twitter, etc. A wide selection of journals (inclusive of 9 subjects, more than 200 journals)

Providing 24-hour high-quality service

User-friendly online submission system

Fair and swift peer-review system

Efficient typesetting and proofreading procedure

Display of the result of downloads and visits, as well as the number of cited articles

Maximum dissemination of your research work

Submit your manuscript at: http://papersubmission.scirp.org/

Or contact jbm@scirp.org 